\title{
Establishing percentile charts for hip joint capsule and synovial cavity thickness in apparently healthy children
}

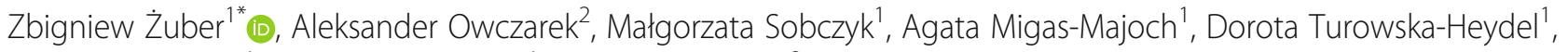
Agnieszka Sternal', Justyna Michalczak and Jerzy Chudek $^{3}$

\begin{abstract}
Background: The usefulness of musculoskeletal ultrasonography (MSUS) in paediatric population is limited by lack of reference values. One of such parameters is hip joint capsule thickness, postulated as an early measure for synovitis. However, the joint capsule is hardly a distinguished structure from slit synovial cavity in patients with little or no fluid collection. Therefore, in patients without effusion, it is more convenient to measure hip joint capsule thickness together with synovial cavity.

The aim of the study was to establish percentile chart for hip joint capsule and synovial cavity thickness (HJC\&SCT) in apparently healthy children.
\end{abstract}

Material and methods: The analysis included 816 US of hip joint in 408 children without musculoskeletal disorders, distributed equally throughout the whole developmental period in 18 one-year subgroups. Hip joints US was performed according to standard protocol including measurement of HJC\&SCT in a single rheumatology centre by three investigators.

Results: The 3rd, 10th, 25th, 50th, 75th, 90th, and 97th HJC\&SCT percentile curves were depicted in the age and height charts for the combined group of girls and boys. The median HJC\&SCT values were increasing with age from 3.7 (C10 - C90: 3.3 - 4.2) $\mathrm{mm}$ in the first year of life up to 6.7 (5.8 - 7.3) in 16 years old, and above. In a similar way the increase was seen with height from $3.9(3.5-4.7) \mathrm{mm}$ in shorter than $95 \mathrm{~cm}$ to $6.9(6.2-7.4) \mathrm{mm}$ in taller than $169 \mathrm{~cm}$ subjects. Intra-observer and inter-observer mean precision was less than 1.8 and $12.5 \%$, respectively.

Conclusion: The developed centile chart for hip joint capsule and synovial cavity thickness in the paediatric population is expected to improve detection of hip joint capsule disorders, including synovitis in juvenile idiopathic arthritis.

Keywords: Ultrasonography, Hip joint, Synovial joint space

\section{Background}

Musculoskeletal ultrasonography (MSUS) is a well-established relevant tool in the management of rheumatic and musculoskeletal diseases [1]. It allows evaluation of intraarticular and periarticular structures including diagnosis of synovial disease [2]. In paediatric rheumatology ultrasonography (US) can detect synovitis in patients with juvenile idiopathic arthritis (JIA) in various joints

\footnotetext{
*Correspondence: zbyszekzuber@interia.pl

'Department of Older Children with subunits of Neurology and Rheumatology,

St. Louis Regional Specialised Children's Hospital, Krakow, Poland

Full list of author information is available at the end of the article
}

involvement (metacarpophalangeal, metatarsophalangeal, interphalangeal, wrist, ankle, knee, subtalar) and differentiated agreement with radiological imaging [3-11]. MSUS has an advantage over clinical examination in the detection of synovitis. It was shown that MSUS may also detect subclinical synovitis $[7,9,10]$, and it persistent form in clinically inactive JIA [11]. Magni-Manzoni et al. showed that MSUS may detect subclinical synovitis in clinically normal joints in JIA patients [5]. They detected synovitis in 86 joints $(5.5 \%)$ in 32 children with JIA performing evaluation of 52 joints [5]. Similarly, Silva et al. diagnosed 
subclinical synovitis using MSUS in 34.4\% of children with JIA [10].

Few studies assessed hip synovitis in JIA patients applying US [7, 10, 11]. In children with JIA and active arthritis of the hip joint MSUS revealed pathological widening of the synovial joint space in $61 \%$ examinations [7]. Others reported only bone irregularities (erosions) in 4 hips, but no subclinical synovitis [11].

Collado et al. [12] in a systematic literature review focused on US as the imaging tool in the diagnosis and management of synovitis in JIA disclosing different definition used for synovitis by authors. US can evaluate synovitis at the anatomic and vascular levels. The grayscale setting enables visualization of synovial hypertrophy and effusion, whereas the power Doppler settings allow for detecting changes in the microvascular blood flow in synovitis. The scoring system developed by the Outcome Measures in Rheumatology (OMERACT) [13] providing definitions of common pathological lesions in patients with inflammatory arthritis, cannot be applied in the paediatric population, as the normal values - percentile charts for healthy children for synovial hypertrophy were not established. Synovial membrane is hardly distinguished from the other structures of hip joint capsule and slit synovial cavity in patients with little [14] or no fluid collection, therefore we have measured the distance from outer surface of the capsule to the cartilage and name it hip joint capsule and synovial cavity thickness (HJC\&SCT). Similar approach was applied by Rohrschneider at al. [15], who measured neck-capsule distance (NCD) of hip anterior recess in 166 asymptomatic children aged from 4 months to 17 years, and correlated it to growth (height).

\section{Aim of the study}

Establishing percentile chart for hip joint capsule and synovial cavity thickness (HJC\&SCT) in apparently healthy children.

\section{Methods}

The analysis included 816 measurements of hip joint capsule thickness in 408 children without musculoskeletal disorders, distributed equally throughout the whole developmental period in 18 one-year subgroups, referred to one rheumatological centre (Department of Older Children with subunits of Neurology and Rheumatology, St. Louis Regional Specialised Children's Hospital in Cracow). Musculoskeletal disorders were excluded on the basis of clinical examination, laboratory findings and follow up observation.

We included patients diagnosed for increased antistreptolysin O (ASO) titre, defective mineralization, back pain, and connective tissue diseases. Patients with symptoms of hip involvement, gait disturbances and limping, asymmetry of body (scoliosis, asymmetry of lower extremities length), and history of developmental disorders (e.g. dysplasia), injuries, transient arthritis (coxitis fugax), juvenile idiopathic arthritis (JIA), however, other rheumatic diseases were excluded.

The ultrasound (US) evaluation of the hip joints was performed according to standard protocol including measurement of hip joint capsule thickness by 3 paediatric rheumatologist trained in musculoskeletal sonography (ZZ, MS and AMM). Data were prospectively collected from July 2010 to June 2016.

The investigators obtained approval for Bioethics Committee (99/KBL/OIL/2010) for performing US measurements in paediatric patients and their use for research. Patients and parents gave informed consent for the performing of US.

\section{Ultrasound examination of the hip joints}

The US evaluation in each patient was performed bilaterally on hip joints. Images were obtained with a Philips model HD 11 XE ultrasonography machine equipped with a 7.5-12 MHz liner transducer (accuracy $0.1 \mathrm{~mm}$ ). A standardized procedure similar to that used by other investigators was followed, a ventral, longitudinal approach was chosen for the hip [16, 17]. Anterior longitudinal imaging is a standard procedure in our centre. During examination a patient lies on his back (supine), with hips in a neutral position, both legs straight, parallel to the ground (couch). Feet laid parallel next to each other at an angle of $90^{\circ}$ to the ground. A linear transducer is applied parallel to the femoral neck, with proximal end located more medially (inclination angle of approx. $20^{\circ}$ ). Obtained images enable visualization of the following structures: acetabulum with cartilaginous acetabular labrum, upper extremity (head) of the femur, femoral neck, front part of the joint capsule (should be parallel to the to the femoral neck), iliofemoral ligament located above the joint capsule, iliopsoas muscle (located above the ligament), tensor fasciae late muscle (partially visible), rectus femoris muscle, and sartorius muscle (located above the iliopsoas and tensor fasciae latae muscle). The joint vascularization is visualized by Color Doppler (CD) and Power Doppler (PD).

We measure a distance between femoral neck and joint capsule (the so-called synovial joint space, SJS) - if visible, and the distance between femoral neck and the external surface of the joint capsule - HJC\&SCT (Fig. 1), as the separate measurement of SJS is difficult in subjects without significant collection of the joint fluid.

\section{Intra-observer variability}

The inter-observer and intra-observer variability was analyzed on the basis of repeated duplicated measurements performed for 17 hip joints in 17 randomly chosen healthy children, independently by 3 sonographers. The 


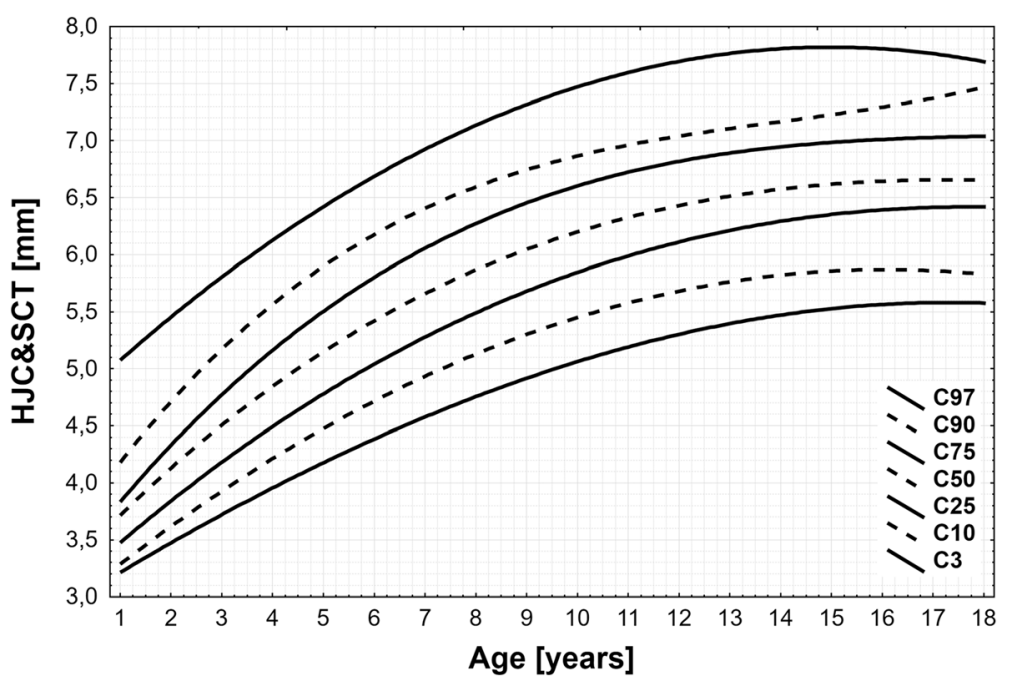

Fig. 1 Hip joint capsule and synovial cavity thickness (HJC\&SCT) centile chart for age

results of previously performed measurements were blinded to the other sonographers.

\section{Statistical analysis}

Statistical analysis was performed using STATISTICA 10.0 PL (StatSoft, Poland, Cracow). Comparison of HJC\&SCT values between left and right side, for each age group, was done with the t-Student test for paired samples. For each age group all required percentiles were calculated. In the case of height 10 percentiles were calculated to divide children into the separable heightgroups. Based on percentiles values the second/third order polynomials with age/height at the $\mathrm{x}$ axis were used to create a centile chart. Based on obtained equations all percentiles for each age/height group were then calculated and are presented in tables. In order to assess the relationship between HJC\&SCT, the linear regression was used. The Cook-Weisberg test and Cameron \& Trivedi's decomposition test was used to test the residuals for heteroskedasticity as well as the violation of skewness and kurtosis assumptions in linear regression. Multicollinearity was evaluated by calculating the variance inflation factor (VIF), which should not exceed 5. As a measure of effect size for regression analysis, we used $\eta^{2}$, which is the proportion of the total variance attributed to an effect. Larger values of $\eta^{2}$ indicate greater influence on the dependent variable.

The intra-observer variability $(\mathrm{mm})$ was calculated as a mean difference with $95 \%$ confidence interval of two following HJC\&SCT measurement in a set of 34 randomly chosen patients. Intra-rater and inter-observer variability $\mathrm{CV}$ was calculated for this set of patients according to Chesher [18].

\section{Results}

The analysis of hip joint capsule and synovial cavity thickness (HJC\&SCT) included 816 measurements of hip joint capsule thickness in 408 apparently healthy children $(254(62,2 \%)$ girls and $154(37,8 \%)$ boys), in 18 one-year subgroups, equally distributed through the whole of developmental period.

Similar values were observed for corresponding measurements of the left and right hip joints, all $\mathrm{p}$ values of the $\mathrm{t}$-Student test were above 0.05 . Mean difference of HJC\&SCT values between left and right hip joints, for all children, was $0.02 \pm 0.31 \mathrm{~mm}(95 \% \mathrm{CI}:-0.01 \div 0.05$; $p=0.11$ ), and maximum difference of $0.5 \mathrm{~mm}$. Therefore the analysis was performed without separation for the left and right joint measurements. In addition we showed no significant difference for girls and boys (mean difference of HJC\&SCT values between groups was $-0.09 \mathrm{~mm}$ with $95 \%$ CI: $-0.25 \div 0.06)$. This justified the combine analysis for both genders.

The median values of HJC\&SCT were increasing with age from 3.7 (C10-C90: $3.3-4.2) \mathrm{mm}$ in the first year of life up to $6.7(5.8-7.3) \mathrm{mm}$ in 16 years old, and then remained constant in older children (Table 1 and Fig. 1). In a similar way median values of HJC\&SCT were increasing with height from $3.9(3.5-4.7) \mathrm{mm}$ in shorter than $95 \mathrm{~cm}$ to $6.9(6.2-7.4) \mathrm{mm}$ in taller than $169 \mathrm{~cm}$ (Table 1 and Fig. 2). Similar HJC\&SCT values were observed for corresponding height groups of boys and girls.

There was not any patient with synovial effusion, therefore the synovial joint space was not measured.

\section{Inter-observer and intra-observer variability}

We found a high level of agreement between and within investigators. The intra-observer variability was calculated 
Table 1 The values of 3rd, 10th, 25th, 50th, 75th, 90th, and 97th of hip joint capsule and synovial cavity thickness (HJC\&SCT) for age and height

\begin{tabular}{|c|c|c|c|c|c|c|c|c|}
\hline & \multirow{2}{*}{$\begin{array}{l}\text { Number of } \\
\text { subjects }\end{array}$} & \multicolumn{7}{|c|}{ Percentiles } \\
\hline & & C97 & C90 & $\mathrm{C} 75$ & C50 & $\mathrm{C} 25$ & $\mathrm{C} 10$ & C3 \\
\hline \multicolumn{9}{|l|}{ Age [yrs] } \\
\hline 1 & 17 & 5.07 & 4.18 & 3.83 & 3.71 & 3.47 & 3.29 & 3.21 \\
\hline 2 & 13 & 5.45 & 4.71 & 4.33 & 4.13 & 3.84 & 3.62 & 3.47 \\
\hline 3 & 29 & 5.80 & 5.17 & 4.77 & 4.51 & 4.18 & 3.93 & 3.72 \\
\hline 4 & 27 & 6.13 & 5.56 & 5.16 & 4.85 & 4.49 & 4.21 & 3.95 \\
\hline 5 & 20 & 6.42 & 5.90 & 5.50 & 5.15 & 4.78 & 4.47 & 4.18 \\
\hline 6 & 24 & 6.69 & 6.17 & 5.79 & 5.42 & 5.04 & 4.71 & 4.38 \\
\hline 7 & 21 & 6.93 & 6.40 & 6.04 & 5.66 & 5.27 & 4.93 & 4.58 \\
\hline 8 & 23 & 7.14 & 6.59 & 6.25 & 5.87 & 5.49 & 5.13 & 4.75 \\
\hline 9 & 23 & 7.32 & 6.74 & 6.42 & 6.06 & 5.67 & 5.30 & 4.92 \\
\hline 10 & 22 & 7.47 & 6.86 & 6.55 & 6.21 & 5.84 & 5.45 & 5.06 \\
\hline 11 & 22 & 7.60 & 6.95 & 6.66 & 6.35 & 5.98 & 5.57 & 5.19 \\
\hline 12 & 23 & 7.70 & 7.02 & 6.73 & 6.46 & 6.10 & 5.68 & 5.30 \\
\hline 13 & 26 & 7.77 & 7.09 & 6.78 & 6.55 & 6.20 & 5.76 & 5.40 \\
\hline 14 & 30 & 7.81 & 7.14 & 6.81 & 6.62 & 6.28 & 5.82 & 5.47 \\
\hline 15 & 26 & 7.83 & 7.20 & 6.82 & 6.67 & 6.34 & 5.85 & 5.53 \\
\hline 16 & 28 & 7.81 & 7.25 & 6.81 & 6.71 & 6.38 & 5.86 & 5.57 \\
\hline 17 & 24 & 7.77 & 7.33 & 6.79 & 6.74 & 6.40 & 5.85 & 5.58 \\
\hline 18 & 10 & 7.70 & 7.41 & 6.75 & 6.75 & 6.40 & 5.82 & 5.58 \\
\hline \multicolumn{9}{|l|}{ Height $[\mathrm{cm}]$} \\
\hline$<95$ & 39 & 5.23 & 4.69 & 4.06 & 3.89 & 3.62 & 3.47 & 3.23 \\
\hline 95-106 & 42 & 6.01 & 5.63 & 5.12 & 4.79 & 4.41 & 4.18 & 3.93 \\
\hline $107-117$ & 42 & 6.44 & 6.11 & 5.65 & 5.27 & 4.84 & 4.58 & 4.30 \\
\hline $118-127$ & 40 & 6.82 & 6.51 & 6.09 & 5.69 & 5.22 & 4.94 & 4.61 \\
\hline 128-137 & 38 & 7.10 & 6.77 & 6.39 & 5.99 & 5.50 & 5.21 & 4.83 \\
\hline 138-148 & 41 & 7.38 & 7.02 & 6.64 & 6.28 & 5.77 & 5.48 & 5.03 \\
\hline 149-156 & 42 & 7.64 & 7.22 & 6.85 & 6.55 & 6.04 & 5.74 & 5.21 \\
\hline $157-162$ & 40 & 7.80 & 7.31 & 6.94 & 6.69 & 6.18 & 5.90 & 5.31 \\
\hline 163-168 & 40 & 7.90 & 7.36 & 6.99 & 6.78 & 6.29 & 6.01 & 5.37 \\
\hline$\geq 169$ & 44 & 8.05 & 7.41 & 7.03 & 6.91 & 6.43 & 6.17 & 5.44 \\
\hline
\end{tabular}

for each sonographer separately [mean difference $(95 \% \mathrm{CI}): 0(-0.34-0.34) ; 0.04(-0.29-0.38) ;-0.01$ $(-0.35-0.33) \mathrm{mm}$; corresponding to intra-rater $\mathrm{CV}$ : 0.5\%; 0.7 and $1.8 \%$ ]. The inter-observer variability $\mathrm{CV}$ and correlation coefficient between consecutive pairs of three corresponding sonographers were as follows: $12.3 \%(r=0.981 ; p<0.001), 12.4 \%(r=0.974 ; p<0.001)$ and $12.5 \%(r=0.973 ; p<0.001)$.

\section{Percentile chart}

Percentiles for HJC\&SCT were calculated for each one year age group and based on this values centile chart against age presented on Fig. 1 were created. Based on those equations all percentiles for each age group were then calculated and are presented in the Table 1. The range of centile values changes from $3.21 \mathrm{~mm}$ for one year-old children to $7.83 \mathrm{~mm}$ for fifteen year-old children.

In a similar way percentiles for HJC\&SCT were calculated for 10 equinumerous, separable height groups and are presented on Fig. 2. Based on fitted equations all percentiles for each height group were then calculated and shown in Table 1 . The range of centile values changes from $3.22 \mathrm{~mm}$ for the shortest children to $8.05 \mathrm{~mm}$ for the tallest children.

\section{Regression analyses}

Linear regression coefficients were calculated for the relationship between HJC\&SCT and age [for each year $\mathrm{HJC} \& \mathrm{SCT}$ raised by $\left.{ }^{\circ}=0.048\left(\mathrm{SE}\left({ }^{\circ}\right)=0.016 ; p<0.01\right)\right]$ and height [for each centimetre of height HJC\&SCT raised by $\left.{ }^{\circ}=0.022\left(\operatorname{SE}\left(^{\circ}\right)=0.003 ; p<0.001\right)\right]$. Height had stronger than age effect on HJC\&SCT $\left(\eta^{2}=0.146\right.$ and $\eta^{2}=0.024$; respectively). A proper usage of the regression model was confirmed by the Cameron\&Trtivedi's test $\left(\left.\right|^{2}=12.82 ; p=0.118\right)$.

\section{Discussion}

To the best of our knowledge this is the largest study that analysed the hip joint capsule thickness (measured together with slit synovial cavity) in a healthy paediatric population and the only one that created the percentile chart for age and height. Our study revealed that the hip joint capsule thickness is more related to height than age and not affected by gender. This allows to score the thickness of hip capsule in the Caucasian paediatric patients, and detect variety of synovial abnormalities, including inflammatory (synovitis) and non-inflammatory changes (eg. mucopolysaccharidosis $[19,20]$ ), before irreversible structural changes in cartilage develop [21]. It is important from clinical point of view, as hip joints are considered difficult for clinical detection of synovitis in JIA patients [22]. While, its occurrence may change the initial diagnosis from oligoarticular to polyarticular category, and a long term prognosis.

Routinely performed X-ray imaging is not useful in the early stage of arthritis due to the lack of sensitivity for detection of synovitis and synovial effusion. Only magnetic resonance (MR) and US imaging are recommended in patients with synovial involvement. Laurell et al. demonstrated good correlation of anterior and posterior capsular distance between the US and MR in spontaneous external rotation of $10-15^{\circ}$ and in internal rotation of $45^{\circ}$ [23].

Early diagnosis of JIA (especially polyarticular) and introduction of the therapy with disease-modifying antirheumatic drugs (DMARDs) - usually methotrexate the current 'gold standard' therapy, is improving the 


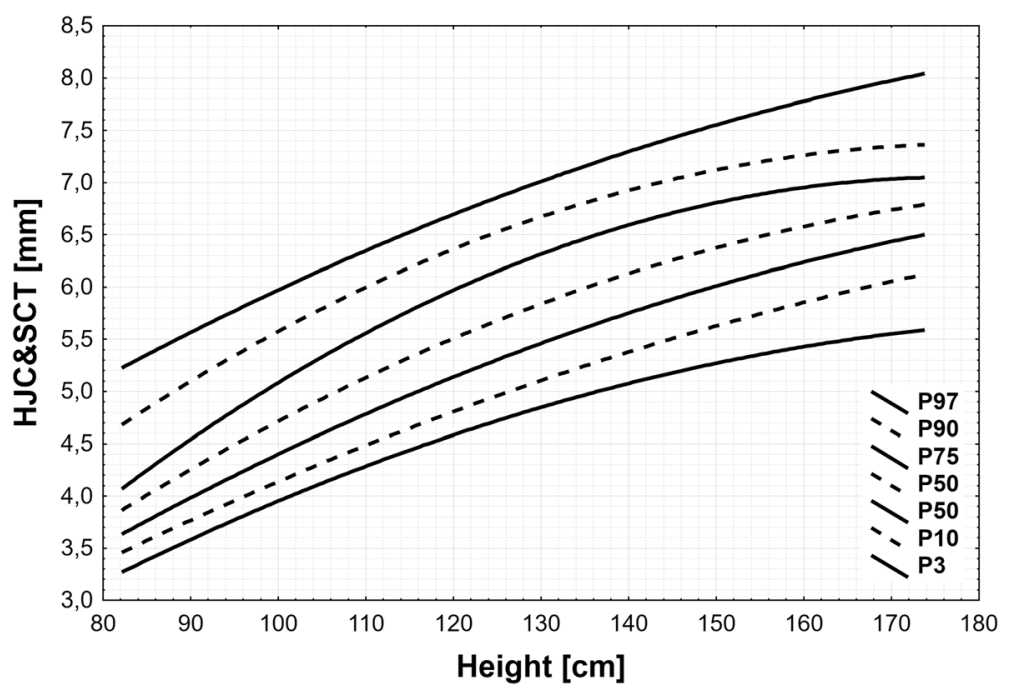

Fig. 2 Hip joint capsule and synovial cavity thickness (HJC\&SCT) centile chart for height

long-term outcome. The shorter interval between symptom onset and the early initiation of aggressive treatment regimen were associated with less joint erosions in the follow-up period [24, 25]. Involvement of hip joints, frequent in JIA children with enthesitis-related arthritis or polyarthritis subtypes, is related with worse long-term prognosis and increased risk for disability [26], and subsequent hip arthroplasty in young adults [27]. Therefore, potentially hip US with HJC\&SCT measurement may be apply for detection of subclinical synovitis even without effusion for selection of patients and that can most benefit from more aggressive therapy. HJC\&SCT measurement might also be useful for synovitis monitoring during the therapy. However, these hypotheses require prospective studies.

We would like to stress that HJC\&SCT measurement is quite ease for performing. As previously shown, the measurement (anterior and posterior capsular distance) is slightly affected by rotation [23]. Therefore, it should be performed is one position, regardless the difference between external rotation and the neutral position was not significant [15]. A more important seems to be intersonographer variability. In our study, the inter-observer variability was less than $12.5 \%$ and much greater than intra-observer variability (less than $1.8 \%$ ), suggesting some difference in the transducer positioning by sonographers. Therefore, optimally repeated measurements during patients follow-up in the centre, should be performed by a single sonographer.

The main limitation of our study is the lack of comparative analysis between US and another imaging modality as MR, which is believed to be the 'gold standard' in musculoskeletal imaging. However, such a comparison has been previously performed, showing good correlation [23]. Furthermore, the sample size of our cohort is was too small to reveal subtle differences between boys and girls in the early pubertal period. Finally, we have included Caucasians only. Consequently the presented centile chart have to be used with caution for non-Caucasian populations.

\section{Conclusion}

The developed centile chart for hip joint capsule and synovial cavity thickness in the paediatric population is expected to improve detection of hip joint capsule disorders, including synovitis in juvenile idiopathic arthritis.

\section{Abbreviations}

CD: Color doppler; DMARDs: Disease-modifying antirheumatic drugs; HJC\&SCT: Hip joint capsule and synovial cavity thickness; JIA: Juvenile idiopathic arthritis; MRI: Magnetic resonance imaging; MSUS: Musculoskeletal ultrasonography; PD: Power doppler; US: Ultrasonography

\section{Acknowledgment}

None.

Funding

None.

Availability of data and materials

The surveys are available from the authors by request.

\section{Authors' contributions}

ZZ conceived of the study, performed ultrasound, collected and developed data and participated in its design and coordination of draft and final version of the manuscript. AO participated in the study design, collected and developed data and performed the statistical analysis. MS performed ultrasound, collected and developed data and participated in its design and coordination of draft. AMM performed ultrasound, collected and developed data. DTH collected and developed data and participated in study design and coordination of draft. AS and JM was involved in data collection. JC conceived of the study, and participated in its design and coordination and helped to draft the manuscript and data analysis. All authors read and approved the final manuscript. 


\section{Competing interests}

The authors declare that they have no competing interests.

\section{Consent for publication}

Not applicable.

\section{Ethics approval and consent to participate}

The investigators obtained approval for Bioethics Committee (99/KBL/OIL/2010) for performing US measurements in paediatric patients, and their use for research.

\section{Author details}

'Department of Older Children with subunits of Neurology and Rheumatology, St. Louis Regional Specialised Children's Hospital, Krakow, Poland. '2Department of Statistics, School of Pharmacy in Sosnowiec, Medical University of Silesia, Katowice, Poland. ${ }^{3}$ Department of Pathophysiology, Medical Faculty in Katowice, Medical University of Silesia, Katowice, Poland.

Received: 13 October 2016 Accepted: 12 January 2017

Published online: 31 January 2017

\section{References}

1. Naredo E, lagnocco A. One year in review: ultrasound in arthritis. Clin Exp Rheumatol. 2016:34:1-10.

2. Conaghan PG. Musculoskeletal ultrasonography: improving our senses. Arthritis Rheum. 2005;53:639-42.

3. Karmazyn B, Bowyer SL, Schmidt KM, Ballinger SH, Buckwalter K, Beam TT, Ying J. US findings of metacarpophalangeal joints in children with idiopathic juvenile arthritis. Pediatr Radiol. 2007;37:475-82.

4. Rooney ME, McAllister C, Burns JF. Ankle disease in juvenile idiopathic arthritis: ultrasound findings in clinically swollen ankles. J Rheumatol. 2009;36:1725-9.

5. Magni-Manzoni S, Epis O, Ravelli A, Klersy C, Veisconti C, Lanni S, Muratore V, Sciré CA, Rossi S, Montecucco C. Comparison of clinical versus ultrasounddetermined synovitis in juvenile idiopathic arthritis. Arthritis Rheum. 2009;61:1497-504.

6. Haslam KE, McCann LJ, Wyatt S, Wakefield RJ. The detection of subclinical synovitis by ultrasound in oligoarticular juvenile idiopathic arthritis: a pilot study. Rheumatology (Oxford). 2010;49:123-7.

7. Frosch M, Foell D, Ganser G, Roth J. Arthrosonography of hip and knee joints in the follow up of juvenile rheumatoid arthritis. Ann Rheum Dis. 2003;62:242-4

8. Rebollo-Polo M, Koujok K, Weisser C, Jurencak R, Bruns A, Roth J. Ultrasound findings on patients with juvenile idiopathic arthritis in clinical remission. Arthritis Care Res (Hoboken). 2011;63:1013-9.

9. Magni-Manzoni S, Scire CA, Ravelli A, Klersy C, Rossi S, Muratore V, Viscont C, Lanni S, Merli P, Montecucco C. Ultrasound-detected synovial abnormalities are frequent in clinically inactive juvenile idiopathic arthritis, but do not predict a flare of synovitis. Ann Rheum Dis. 2013;72:223-8.

10. Bugni Miotto e Silva V, Faquin G, Nicacio A, Regacini R, Lederman $H$, Esteves Hilario MO, Terreri MT. Association between the ultrasonographic and clinical findings in the hips of patients with juvenile idiopathic arthritis. Rev Bras Reumatol. 2013;53:322-7.

11. Bugni Miotto e Silva V, de Freitas Tavares da Silva C, de Aguiar Vilela Mitraud S, Nely Vilar Furtado R, Esteves Hilario MO, Natour J, Terreri MT. Do patients with juvenile idiopathic arthritis in remission exhibit active synovitis on joint ultrasound? Rheumatol Int. 2014;34:937-45.

12. Collado P, Jousse-Joulin S, Alcalde M, Naredo E, D'Agostino MA. Is ultrasound a validated imaging tool for the diagnosis and management of synovitis in juvenile idiopathic arthritis? a systematic literature review. Arthritis Care Res (Hoboken). 2012;64:1011-9.

13. Wakefield RJ, Balint PV, Szkudlarek M, Filippucci E, Backhaus M, D'Agostino MA, Sanchez EN, lagnocco A, Schmidt WA, Bruyn GA, Kane D, O'Connor PJ, Manger B, Joshua F, Koski J, Grassi W, Lassere MN, Swen N, Kainberger F, Klauser A, Ostergaard M, Brown AK, Machold KP, Conaghan PG. Musculoskeletal ultrasound including definitions for ultrasonographic pathology. J Rheumatol. 2005;32:2485-7.

14. Robben SG, Lequin MH, Diepstraten AF, den Hollander JC, Entius CA, Meradji M. Anterior joint capsule of the normal hip and in children with transient synovitis: US study with anatomic and histologic correlation. Radiology. 1999;210:499-507.
15. Rohrschneider WK, Fuchs G, Tröger J. Ultrasonographic evaluation of the anterior recess in the normal hip: a prospective study on 166 asymptomatic children. Pediatr Radiol. 1996;26:629-34.

16. Eich G, Halle F, Hodler J, Seger R, Willi U. Juvenile chronic arthritis: imaging of the knees and hips before and after intraarticular steroid injection. Pediatr Radiol. 1994;24:558-63.

17. Federizzi MS, Ronchezel MV, Hilario MO, Lederman HM, Sawaya S, et al. Ultrasonography in the early diagnosis of hip joint involvement in juvenile rheumatoid arthritis. J Rheumatol. 1997:24:1820-5.

18. Chesher D. Evaluating assay precision. Clin Biochem Rev. 2008;29 Suppl 1:S23-6.

19. Collado RP. Ultrasound imaging in juvenile idiopathic arthritis for the rheumatologist. Clin Exp Rheumatol. 2014;32(1 Suppl 80):S34-41.

20. Żuber Z, Jurecka A, Różdżyńska-Świątkowska A, Migas-Majoch A, Lembas A, Kieć-Wilk B, Tylki-Szymańska A. Ultrasonographic features of hip joints in mucopolysaccharidoses type I and II. PLoS One. 2015;10:e0123792.

21. Magni-Manzoni S. Ultrasound measurement of cartilage thickness in childhood arthritis-target the tissue, tailor the technique. J Rheumatol. 2015;42:360-2.

22. Nistala K, Babar J, Johnson K, Campbell-Stokes P, Foster K, Ryder C, et al. Clinical assessment and core outcome variables are poor predictors of hip arthritis diagnosed by MRI in juvenile idiopathic arthritis. Rheumatology (Oxford). 2007:46:699-702.

23. Laurell $L$, Hochbergs $P$, Rydholm U, Wingstrand $H$. Capsular distance in the hip of the healthy child - normal values with sonography and MR imaging. Acta Radiol. 2002;43:213-6.

24. Ravelli A, Ramenghi B, Di Fuccia G, Ruperto N, Zonta L, Martini A. Factors associated with response to methotrexate in systemic-onset juvenile chronic arthritis. Acta Paediatr. 1994;83:428-32.

25. Flato B, Aasland A, Vinje O, Forre O. Outcome and predictive factors in juvenile rheumatoid arthritis and juvenile spondyloarthropathy. J Rheumatol. 1998:25:366-75.

26. Rostom S, Amine B, Bensabbah R, Abouqal R, Hajjaj-Hassouni N. Hip involvement in juvenile idiopathic arthritis. Clin Rheumatol. 2008;27:791-4.

27. Mertelsmann-Voss C, Lyman S, Pan TJ, Goodman SM, Figgie MP, Mandl LA. US trends in rates of arthroplasty for inflammatory arthritis including rheumatoid arthritis, juvenile idiopathic arthritis, and spondyloarthritis. Arthritis Rheumatol. 2014:66:1432-9.

\section{Submit your next manuscript to BioMed Central and we will help you at every step:}

- We accept pre-submission inquiries

- Our selector tool helps you to find the most relevant journal

- We provide round the clock customer support

- Convenient online submission

- Thorough peer review

- Inclusion in PubMed and all major indexing services

- Maximum visibility for your research

Submit your manuscript at www.biomedcentral.com/submit 